\title{
Molecular biology of the kallikrein-kinin system: from structure to function
}

J.B. Pesquero ${ }^{1}$ and M. Bader ${ }^{2}$
${ }^{1}$ Departamento de Biofísica, Universidade Federal de São Paulo, São Paulo, SP, Brasil

${ }^{2}$ Max-Delbrück Center for Molecular Medicine, Berlin, Germany

\author{
Correspondence \\ J.B. Pesquero \\ Departamento de Biofísica \\ UNIFESP \\ Rua Botucatu, 862, 7음 andar \\ 04023-062 São Paulo, SP \\ Brasil \\ Fax: 55 (011) 571-5780 \\ E-mail: jbpesq@biofis.epm.br \\ Presented at the II International \\ Symposium on Vasoactive Peptides, \\ Ouro Preto, MG, Brasil, \\ October 6-8, 1997. \\ Publication supported by FAPESP. \\ J.B. Pesquero was the recipient \\ of a post-doctoral fellowship from \\ $\mathrm{CNPq}$ and from the Max-Delbrück \\ Center for Molecular Medicine \\ (MDC).
}

Received February 4, 1998

Accepted March 17, 1998

. . . . . . . . . . . . .

\begin{abstract}
The participation of the kallikrein-kinin system, comprising the serine proteases kallikreins, the protein substrates kininogens and the effective peptides kinins, in some pathological processes like hypertension and cardiovascular diseases is still a matter of controversy. The use of different experimental set-ups in concert with the development of potent and specific inhibitors and antagonists for the system has highlighted its importance but the results still lack conclusivity. Over the last few years, transgenic and gene-targeting technologies associated with molecular biology tools have provided specific information about the elusive role of the kallikrein-kinin system in the control of blood pressure and electrolyte homeostasis. cDNA and genomic sequences for kinin receptors B2 and B1 from different species were isolated and shown to encode G-protein-coupled receptors and the structure and pharmacology of the receptors were characterized. Transgenic animals expressing an overactive kallikrein-kinin system were established to study the cardiovascular effects of these alterations and the results of these investigations further corroborate the importance of this system in the maintenance of normal blood pressure. Knockout animals for B2 and B1 receptors are available and their analysis also points to the role of these receptors in cardiovascular regulation and inflammatory processes. In this paper the most recent and relevant genetic animal models developed for the study of the kallikrein-kinin system are reviewed, and the advances they brought to the understanding of the biological role of this system are discussed.
\end{abstract}

Key words

- Kallikrein

- Kinins

- Bradykinin

- Molecular biology

- Transgenics

\section{Introduction}

The kallikrein-kinin system (KKS) is an intricate endogenous system thought to be involved in the regulation of blood pressure and inflammation, amongst other processes. This system comprises the enzymes kallikreins, the protein precursors kininogens and the potent vasoactive peptides kinins. Kallikreins are serine proteases found in glandular cells, neutrophils and biological fluids and are divided into two main groups: the tissue or glandular kallikrein and the plasma kallikrein. These are different enzymes encoded by distinct genes; they differ in molecular weight, amino acid composition, types of kinins released and, more importantly, function (1). The vasoactive components of this system, the kinins, are released through the action of kallikreins on the kininogens, and they mediate a wide range of physiological actions related to cardiovascular homeostasis, inflammatory and algesic responses, as well as pain-transmit- 
ting mechanisms (1). Pharmacological studies have demonstrated that kinins promote their biological activities through the activation of at least two different receptor subtypes, denominated B1 and B2. Stimulation of the $\mathrm{B} 2$ receptor results in intense vasodilation, increased blood flow and hypotension (1). In the central nervous system, however, bradykinin (BK) promotes systemic vasoconstriction, increased peripheral resistance and hypertensive responses also via stimulation of B2 receptors (2). Other effects mediated by $\mathrm{B} 2$ receptors include contraction of the bronchopulmonary tree, increased sperm motility, release of cytokines, prostacyclin, and nitric oxide, as well as stimulation of cell proliferation (1). BK, kallidin and the other intact kinins can exert their biological function by binding with high affinity to the $\mathrm{B} 2$ receptors whereas the products of the action of the arginine carboxypeptidase (kininase I-activity) on kinins, the $\mathrm{C}$-terminal-arginine truncated kinins, are preferential agonists for the B1 receptor (35). The B1 receptor is believed to mediate several of the inflammatory responses to kinins (1) and, under pathological conditions, contractile effects on visceral smooth muscle (6). The B2 receptors are constitutively expressed and widely distributed throughout mammalian tissues. In contrast, the B1 subtype is very weakly expressed under normal conditions but can be induced in vivo and in vitro by endotoxin, cytokines and growth factors, indicating that these receptors may be important in inflammation and trauma (1). Lately, due to the recent advances in genetic and molecular biology techniques, the role of the KKS in several physiological processes can be analyzed in more detail using different transgenic animal models.

\section{Molecular biology of the kallikrein-kinin system}

In order to generate transgenic animals overexpressing or lacking a protein, previous knowledge about the molecular structure of the gene coding for this protein is necessary. The molecular biology of the KKS of many species like humans, rabbits, rats, and mice, including the kallikreins, the kininogens and the receptors, was clarified over the last decade. The structure of tissue kallikrein genes from different species and of genes for the kininogens was described in detail elsewhere (for review see 7-9). Regarding the kinin receptors, only recently was the cDNA sequence for the rat B2 receptor determined by McEachern et al. (10). The authors used a clonal selection strategy based on the injection of size-selected mRNA from rat uterus into Xenopus laevis oocytes and measurement of a BK-induced chloride current (10). The protein predicted from the cloned sequence belongs to the seven transmembrane $G$ protein-coupled superfamily of receptors. The knowledge of the rat B2 receptor sequence permitted the cloning of the human and mouse $\mathrm{B} 2$ receptor cDNA and genomic clones by a combined approach of PCR using degenerate primers and library screening $(11,12)$. In parallel, based on the sequence homology shared by genes encoding G-protein-coupled receptors and using low-stringency PCR and human genomic DNA, Eggerickx et al. (13) were able to isolate a genomic clone of the human B2 receptor. The isolation and characterization of the genomic structure of the $\mathrm{B} 2$ receptor from rats (14) and other species like humans $(15,16)$ and mice $(17)$ were later achieved. By screening a rat genomic library, we isolated and analyzed the rat BK B2 receptor gene (14). The complete genomic structure for the rat $\mathrm{B} 2$ receptor gene was determined, including exon-intron boundaries and the promoter region (14). Differently from the human B2 receptor gene, which encompasses 3 exons (15), the rat gene was shown to consist of 4 exons spanning $32 \mathrm{~kb}$ of genomic DNA. Exon 3 was shown to be alternatively spliced. The exon 1 sequence of the rat 
B2 gene described by Ma et al. (18) was shown to contain the exon 2 sequence of the gene, and the promoter region proposed by the authors is in fact an intron sequence. Based on the published analysis of the mouse B2 receptor sequence (18), it is likely that the mouse $\mathrm{B} 2$ receptor also contains 4 exons, since its coding sequence is $90 \%$ homologous to the rat homolog and exon 2 and 1 present around $80 \%$ and $70 \%$ homology to the rat exons 3 and 2, respectively. This question must still be addressed by other approaches like primer extension and RNase protection experiments. Using the technique of primer extension analysis we identified the promoter region of the rat $\mathrm{B} 2$ receptor gene and we measured its ability to drive the transcription of a luciferase reporter gene in the BK B2 receptor expressing the cell line NG108-15 (14). A cAMP-responsive element-like sequence, which is also conserved in the human promoter region (15), was identified in the core promoter region and found to be functional (19). We also have shown that the regulatory effect produced by the activated ras protein leading to an increase in the BK B2 receptor number on the cell surface is most likely caused by transcriptional activation of the BK B2 receptor gene since it can be mimicked only using its promoter fused to luciferase as a reporter gene (19). These studies will be continued with the use of deletion mutants containing various lengths of the B2 receptor promoter region cloned in front of the luciferase reporter gene. In the rat B2 receptor gene promoter region, like in the human promoter (15), and most probably in the mouse sequence (17) there are no typical TATA or CCAAT sequences. The genomic organization of the $\mathrm{B} 2$ receptor of different species is shown in Figure 1.

The pharmacology of the $\mathrm{B} 1$ receptor has been studied for a long time (20), although its molecular cloning was performed only very recently. Menke et al. (21) isolated a human $\mathrm{B} 1$ receptor clone from a human embryonic lung fibroblast cDNA library. The authors used the method of injection of sucrose-gradient size-fractionated mRNA from IL-1ß-induced IMR-90 cells into Xenopus laevis oocytes and the photoprotein aequorin as an indicator of the ability of the $\mathrm{B} 1$ agonist desArg ${ }^{10}$-kallidin to mediate $\mathrm{Ca}^{2+}$ mobilization. The isolated sequence was also shown to encode a protein with the characteristic seven transmembrane domains typical of the G-protein-coupled receptors but shared a rather low sequence identity with the bradykinin B2 receptor. In the following months, B1 receptors from other species were also cloned and characterized (22-26). All the different B1 receptors isolated were shown to possess high affinity for the B1 agonists

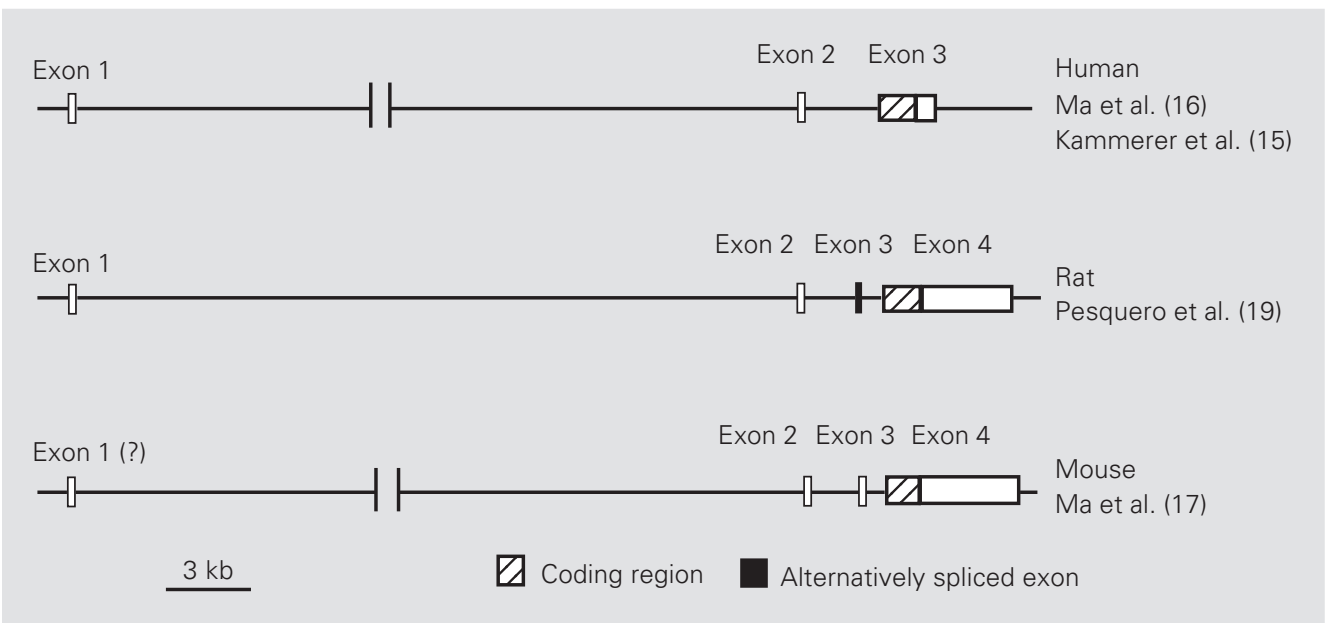

Figure 1 - Genomic organization of human, rat and mouse bradykinin B2 receptors. The mouse gene structure is proposed based on the sequence homology to exons 2 and 3 of the rat gene. The length of intron 1 (25 $\mathrm{kb})$ is only known for the rat gene (19). 
desArg ${ }^{10}$-kallidin and desArg'-BK and low affinity for the B2 agonists. Furthermore, they presented a high degree of amino acid identity but displayed some prominent differences. For instance, rat (27) and mouse B1 $(26,28)$ receptors have an insertion of 11 and 8 amino acids, respectively, in the first intracellular loop when compared to the human $(24,25,28)$ and rabbit (22) sequences. In addition, the rodent $\mathrm{B} 1$ receptors are shortened at the C-terminus due to a translational frameshift $(26,28)$. Since the pharmacology of rodent B1 receptors differs from that of the human receptor concerning the agonists desArg ${ }^{9}$-BK and desArg ${ }^{10}$-kallidin (28), this difference in pharmacological profile may be attributed to these sequence differences in the receptors.

\section{Transgenic and knockout models for the kallikrein-kinin system}

There are two different approaches used to generate an alteration in the genome of an animal: the microinjection of DNA into the nucleus of a fertilized oocyte and targeted modification of a gene in its chromosomal location by homologous recombination in embryonic stem (ES)-cells. The rationale for these approaches is presented by Bader (29) in his review.

\section{Tissue kallilkrein}

Several animal models overexpressing the human tissue kallikrein gene were established using various DNA constructs, driving the kallikrein expression to different tissues. Transgenic mice carrying the human kallikrein gene under the control of the mouse metallothionein metal-responsive promoter expressed the human protein in several organs and, similarly to the model overexpressing the B2 receptor (see below), displayed significantly lowered blood pressure compared to control mice (30). Transgene expression in the mice was checked by spe- cific radioimmunoassay and ELISA for human tissue kallikrein. The decreased blood pressure could be restored to normal levels following administration of aprotinin, a potent kallikrein inhibitor. We also used the same DNA construct to generate a transgenic rat model overexpressing the human tissue kallilkrein (31). The expression of the construct was subsequently established in several tissues including the heart, kidney, lung, and brain by a specific RNase protection assay. Human kallikrein could be detected in the urine of transgenic animals by species-specific antibodies. Cardiovascular parameters were measured in conscious, freely moving animals by telemetric recording. The rats expressing human kallikrein had a lower 24-h mean arterial pressure in comparison to control rats $(5-10 \mathrm{mmHg})$. Significantly, the day/night rhythm in blood pressure was blunted in the transgenic animals. In contrast, the circadian rhythms of heart rate and locomotor activity were normal (31). Although these two animal models overexpressing the human tissue kallikrein were produced in the same manner and had the transgene expression under the control of the same promoter (mouse metallothionein), they displayed striking differences concerning blood pressure levels. Whereas transgene expression resulted in a strong reduction in blood pressure in the mouse model, in the rat model the transgene expression produced a more moderate effect. This discrepancy can be attributed in part to the fact that mouse kininogen is a better substrate for human kallikrein than the rat substrate due to the presence of a proline residue in P2' in the rat molecule (32). In another mouse model, the expression of human tissue kallikrein was targeted to the liver by the use of a mouse albumin promoter (33). The generated animals maintained high levels of the human enzyme in the circulation and were chronically hypotensive, presenting blood pressure levels about $17 \mathrm{mmHg}$ lower than those of control littermates (33). Trans- 
genic mice harboring the human tissue kallikrein gene under the control of its native promoter were also generated (33). Tissue distribution of the transgene followed the same pattern as in human tissues but the animals displayed normal blood pressure values.

Another component of the KKS, the kallikrein-binding protein, was also used for the production of transgenic mice (34). Transgenic animals expressing this protein under the control of the mouse metallothionein promoter were hypotensive when compared to the control litters. This paradoxical effect is explained by the authors by a kallikreinindependent vasodilatory action of the kallikrein-binding protein.

\section{B2 receptor}

Few transgenic animal models have been generated with alteration in the B2 receptor gene. In order to obtain more information on the physiological function of bradykinin, Wang et al. (35) generated a mouse model harboring the human bradykinin $\mathrm{B} 2$ receptor under the control of the Rous sarcoma virus 3'-LTR promoter. The animals expressed the human gene in different tissues and presented a significant reduction of blood pressure compared to control littermates. Although the transgene expression was not quantified or normalized with any other endogenous gene, for instance the endogenous B2 receptor, the amount of human gene expression was sufficient to produce a significant hypotensive effect (35). The blood pressure effect was caused by the presence of the transgene since it was dependent on the gene dose and could be blunted by the administration of the B2 receptor antagonist HOE-140. Moreover, intra-arterial bolus injection of bradykinin produced more pronounced vasodepressor effects on the blood pressure of transgenic animals. Another approach used to study the physiological role of the B2 receptor was the genetic ablation of this gene by homologous recombination in stem cells. The bradykinin B2 receptor knockout model was generated in 1994 by Borkowski et al. (36). The absence of $\mathrm{B} 2$ receptor in this animal did not render it infertile and did not produce any changes in morphology or litter size, ruling out an essential role for this receptor in reproduction and ontogenesis (36). However, the lack of response to bradykinin in the uterine contraction assay and in studies of depolarization of the superior cervical ganglia performed in this model was instrumental to demonstrate the existence of only one B2 receptor gene. The possibility still remains that multiple $\mathrm{B} 2$ receptor subtypes could be produced in different tissues by alternative splicing of the gene, at least in rats (14), leading to the generation of proteins with a distinct $\mathrm{N}$-terminus, as demonstrated by differential utilization of AUG codons present in exons 3 and 4 (37) of the rat B2 gene. Although no reference to alterations in blood pressure was made in the original paper describing the $\mathrm{B} 2$ receptor knockout model (36), some authors have reported an increase in blood pressure in these animals (38). Furthermore, evidence has been presented suggesting a role of kinins in preventing salt-sensitive hypertension, whereby the B2 knockout mice displayed a greater hypertensive response to chronic sodium intake compared to control animals (39).

\section{B1 receptor}

So far, due to the very recent cloning of the genes coding for the $\mathrm{B} 1$ receptor, only the knockout model has been described. To study the physiologic role of the B1 receptor in physiopathologic states like inflammation and also in cardiac diseases, we generated a mouse model lacking the $\mathrm{B} 1$ receptor gene (40). To generate the knockout mice, the isolated murine B1-receptor gene (26) was mutated in vitro by replacing the coding region with the neomycin resistance gene. 
This construct was transfected into ES-cells, which were subsequently screened for neomycin and ganciclovir resistance. The resistant clones were checked by PCR for homologous recombinants, i.e., cells containing the mutated bradykinin-B1 allele at the correct chromosomal position. Homozygous animals were shown to be viable and to present normal development. Gene ablation was confirmed by PCR and Southern blot assays, checked at the RNA level by RNase protection assays and functionally determined by the lack of activity of B1 agonists in stomach, ileum, and uterus muscle contraction assays. Mean arterial pressure was measured in awake mice and found not to differ from the control littermates, ruling out the participation of the $\mathrm{B} 1$ receptor in the control of blood pressure under normal conditions (40).

\section{Conclusions}

The use of genetically engineered animals is an invaluable tool for unraveling the pathogenesis of complex cardiovascular diseases and many aspects of mammalian biology. Although the molecular characterization of the kallikrein-kinin system was started relatively recently, many transgenic animal models with alterations in the system have been generated. The results presented here and the data which will still be generated with these and other models will be instrumental in elucidating the role of the proteins of the kallikrein-kinin system for the control of cardiovascular homeostasis and of inflammatory processes, both important factors in the etiology of the most common human diseases.

\section{References}

1. Bhoola KD, Figueroa $C D$ \& Worthy $K$ (1982). Bioregulation of kinins: kallikreins, kininogens and kininases. Pharmacological Reviews, 44: 1-80.

2. Lindsey CJ, Nakaie CR \& Martins DT (1989). Central nervous system kinin receptors and the hypertensive response mediated by bradykinin. British Journal of Pharmacology, 97: 763-768.

3. Roberts RA (1989). Bradykinin receptors: characterization, distribution and mechanisms of signal transduction. Progress in Growth Factor Research, 1: 237-252.

4. Farmer SG \& Burch RM (1992). Biochemical and molecular pharmacology of kinin receptors. Annual Review of Pharmacology and Toxicology, 32: 511-536.

5. Burch RM \& Kyle DJ (1992). Recent developments in the understanding of bradykinin receptors. Life Sciences, 50: 829838.

6. Feres $T$, Paiva ACM \& Paiva TB (1992). $\mathrm{BK}_{1}$ and $\mathrm{BK}_{2}$ bradykinin receptors in the rat duodenum smooth muscle. British Journal of Pharmacology, 107: 991-995.

7. Scicli AG, Carbini LA \& Carretero OA (1993). The molecular biology of the kallikrein-kinin system: II. The rat gene family. Journal of Hypertension, 1: 775-780.

8. Carretero OA, Carbini LA \& Scicli G (1993).
The molecular biology of the kallikreinkinin system: I. General description, nomenclature and the mouse gene family. Journal of Hypertension, 11: 693-697.

9. Carbini LA, Scicli AG \& Carretero $O A$ (1993). The molecular biology of the kallikrein-kinin system: III. The human kallikrein gene family and kallikrein substrate. Journal of Hypertension, 11: 893-898.

10. McEachern AE, Shelton ER, Bhakta $S$, Obernolte R, Bach C, Zuppan P, Fujisaki J, Aldrich RW \& Jarnagin K (1991). Expression cloning of a rat B2 bradykinin receptor. Proceedings of the National Academy of Sciences, USA, 88: 7724-7728.

11. Hess JF, Borkowski JA, Young GS, Strader CD \& Ransom RW (1992). Cloning and pharmacological characterization of a human bradykinin (BK-2) receptor. Biochemical and Biophysical Research Communications, 184: 260-268.

12. Mclntyre $P$, Phillips $E$, Skidmore $E$, Brown $M$ \& Webb M (1993). Cloned murine bradykinin receptor exhibits a mixed B1 and B2 pharmacological selectivity. Molecular Pharmacology, 44: 346-355.

13. Eggerickx D, Raspe E, Bertrand D, Vassart G \& Parmentier M (1992). Molecular cloning, functional expression and pharmacological characterization of a human brady- kinin B2 receptor gene. Biochemical and Biophysical Research Communications, 187: 1306-1313.

14. Pesquero JB, Lindsey CJ, Zeh K, Paiva ACM, Ganten D \& Bader M (1994). Molecular structure and expression of rat bradykinin B2 receptor gene. Evidence for alternative splicing. Journal of Biological Chemistry, 269: 26920-26925.

15. Kammerer $S$, Braun A, Arnold N \& Roscher AA (1995). The human bradykinin B2 receptor gene: full length cDNA, genomic organization and identification of the regulatory region. Biochemical and Biophysical Research Communications, 211: 226-233

16. Ma JX, Wang DZ, Ward DC, Chen L, Dessai T, Chao J \& Chao L (1994). Structure and chromosomal localization of the gene (BDKRB2) encoding human bradykinin $B_{2}$ receptor. Genomics, 23: 362-369.

17. Ma J, Wang D, Chao L \& Chao J (1994). Cloning, sequence analysis and expression of the gene encoding the mouse bradykinin $B_{2}$ receptor. Gene, 149: 283288.

18. Wang D, Ma J, Chao L \& Chao J (1994). Molecular cloning and sequence analysis of rat bradykinin $B_{2}$ receptor gene. Biochimica et Biophysica Acta, 1219: 171-174. 
19. Pesquero JB, Lindsey CJ, Paiva ACM, Ganten D \& Bader M (1996). Transcriptional regulatory elements in the rat bradykinin B2 receptor gene. Immunopharmacology, 33: 36-41.

20. Regoli D \& Barabe J (1980). Pharmacology of bradykinin and related kinins. Pharmacological Reviews, 32: 1-46

21. Menke JG, Borkowski JA, Bierilo KK, Macneil T, Derrick AW, Schneck KA, Ransom RW, Strader CD, Linemeyer DL \& Hess JF (1994). Expression cloning of a human B1 bradykinin receptor. Journal of Biological Chemistry, 264: 21583-21586.

22. Macneil T, Bierilo KK, Menke JG \& Hess JF (1995). Cloning and pharmacological characterization of a rabbit bradykinin B1 receptor. Biochimica et Biophysica Acta, 1264: 223-228.

23. Bachvarov DR, Hess JF, Menke JG, Larrivee JF \& Marceau F (1996). Structure and genomic organization of the human B1 receptor gene for kinins (BDKRB1). Genomics, 33: 374-381.

24. Yang $X \&$ Polgar $P$ (1996). Genomic structure of the human bradykinin B1 receptor gene and preliminary characterization of its regulatory regions. Biochemical and Biophysical Research Communications, 222: 718-725.

25. Chai KX, Ni A, Wang D, Ward DC, Chao J \& Chao L (1996). Genomic DNA sequence, expression, and chromosomal localization of the human B1 bradykinin receptor gene BDKRB1. Genomics, 31: 5157

26. Pesquero JB, Pesquero J, Oliveira SM, Roscher AA, Metzger R, Ganten D \& Bader M (1996). Molecular cloning and functional characterization of a mouse bradykinin B1 receptor gene. Biochemical and Biophysical Research Communications, 220: 219-225.

27. Pesquero JB, Oliveira SM, Pesquero J, Roscher AA, Metzger R, Ganten D \& Bader M (1996). Molecular cloning of rodent bradykinin B1 receptor genes. Peptide Receptors Symposium, July 28-August 1, Montreal, Quebec, Canada (Abstract II.0.5).

28. Hess JF, Derrick AW, Macneil T \& Borkowski JA (1996). The agonist selectivity of a mouse B1 bradykinin receptor differs from human and rabbit B1 receptors. Immunopharmacology, 33: 1-8.

29. Bader M (1998). Transgenic animal models for the functional analysis of vasoactive peptides. Brazilian Journal of Medical and Biological Research, 31: 1171-1183.

30. Wang J, Xiong W, Yang Z, Davis T, Dewey MJ, Chao J \& Chao L (1994). Human tissue kallikrein induces hypotension in transgenic mice. Hypertension, 23: 236243.

31. Bader M, Araujo RC, Oliveira SM, Baltatu O, Chao J, Chao L, Hoffmann S, Plehm R, Ganten D \& Pesquero JB (1997). Circadian rhythm of blood pressure is abolished in human tissue kallikrein transgenic rats. Hypertension, 30: 498 (Abstract).

32. Chagas JR, Hirata IY, Juliano MA, Xiong W, Wang C, Chao J, Juliano L \& Prado ES (1992). Substrate specificities of tissue kallikrein and T-kininogenase: their possible role in kininogen processing. Biochemistry, 31: 4969-4974.

33. Chao J \& Chao L (1996). Functional analysis of human tissue kallikrein in transgenic mouse models. Hypertension, 27 (Part 2): 491-494.
34. Chen LM, Ma JX, Liang YM, Chao L \& Chao J (1996). Tissue kallikrein-binding protein reduces blood pressure in transgenic mice. Journal of Biological Chemistry, 271: 27590-27594.

35. Wang DZ, Chao L \& Chao J (1997). Hypotension in transgenic mice overexpressing human bradykinin B2 receptor. Hypertension, 29: 488-493.

36. Borkowski JA, Ransom RW, Seabrook GR, Trumbauer M, Chen H, Hill RG, Strader CD \& Hess JF (1995). Targeted disruption of a B2 bradykinin receptor gene in mice eliminates bradykinin action in smooth muscle and neurons. Journal of Biological Chemistry, 270: 1370613710 .

37. AbdAlla S, Godovac-Zimmermann J, Braun A, Roscher AA, Muller-Esterl W \& Quitterer U (1996). Structure of bradykinin B2 receptors amino terminus. Biochemistry, 35: 7514-7519.

38. Madeddu P, Varoni MV, Emanueli C, Paci MV, Fulgheri PD, Sarzani R \& Glorioso N (1997). Enhanced vasopressor response to angiotensin II in mice with disruption of bradykinin B2-receptor gene. Hypertension, 30: 494 (Abstract).

39. Alfie ME, Yang XP, Hess $F$ \& Carretero OA (1996). Salt-sensitive hypertension in bradykinin B2 receptor knockout mice. Biochemical and Biophysical Research Communications, 224: 625-630.

40. Bader M, Araujo RC, Oliveira SM, Kettritz R, Walther T \& Pesquero JB (1997). Phenotypic characterization of mice lacking the kinin B1 receptor. Hypertension, 30: 998 (Abstract). 